\title{
Синдром Рейно
}

\section{как мультидисциплинарная проблема}

\section{Алекперов Р.Т.}

Алекперов Ризван Таир оглы -

д-р мед. наук,

профессор кафедры терапии

факультета усовершенствования

врачей' ${ }^{1}$ ст. науч. сотр. ${ }^{2}$

$\triangle 129110$, г. Москва, ул. Щепкина, 61/2,

Российская Федерация.

Тел.: +7 (495) 6816840.

E-mail: ralekperov@list.ru
Синдром Рейно широко распространен в популяции: его частота составляет в среднем 3-5\%. Он подразделяется на первичный, с дебютом преимущественно в детском и подростковом возрасте, и вторичный, развивающийся в более старшей возрастной группе. Вторичный синдром Рейно ассоциируется с системными ревматическими заболеваниями, эндокринной и гематологической патологией, отдельными инфекциями. Он также может быть обусловлен экзогенными факторами. В этой связи данное состояние часто встречается в практике ревматологов, педиатров, инфекционистов, гематологов и врачей других специальностей. В лекции подробно излагаются современные подходы к диагностике и дифференциальной диагностике синдрома Рейно.

Ключевые слова: синдром Рейно, диагностика, дифференциальная диагностика.

' ГБУЗ МО «Московский областной научно-исследовательский клинический институт им. М.Ф. Владимирского»; 129110, г. Москва, ул. Щепкина, 61/2, Российская Федерация

2 ФГБНУ «Научно-исследовательский институт ревматологии им. В.А. Насоновой»; 115522, г. Москва, Каширское шоссе, 34А, Российская Федерация

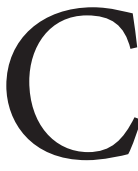

индром Рейно (СР) представляет собой эпизоды преходящей дигитальной ишемии вследствие вазоспазма дигитальных артерий, прекапиллярных артериол и кожных артериовенозных шунтов под влиянием холодной температуры и эмоционального стресса.

Клиническое значение СР обусловлено высокой распространенностью в популяции и частой ассоциацией с другими, нередко угрожающими жизни больных, заболеваниями и состояниями (табл. 1).

Популяционные исследования показали, что частота СР в значительной степени различается между отдельными странами, при этом среди женщин СР встречается чаще, чем среди мужчин (табл. 2) [1-13]. В России эпидемиологических исследований не проводилось, но как свидетельствует наш опыт, пропорция женщин и мужчин с СР такая же, как и в странах Северной Европы. В Европе наибольшая частота СР отмечается в Великобритании, Швеции и Франции, а наименьшая - в Испании и Италии. Эти данные подтверждают известную гипотезу о том, что частота СР существенно выше в районах с относительно холодными климатическими условиями, чем в регионах с теплым климатом [14]. У женщин СР обычно дебютирует в более раннем возрасте, чем у мужчин [9]. В детском возрасте и у лиц старше 50 лет доли мужчин и женщин практически уравновешиваются $[15,16]$. В возрасте старше 60 лет СР развивается только в $0,1-1 \%$ случаев [17]. 
Патофизиология СР не вполне ясна, и, по-видимому, СР следует рассматривать как мультифакториальное состояние. Считается, что причиной чрезмерно выраженного вазоспазма в ответ на провоцирующие стимулы служит дефект центральных и локальных механизмов регуляции сосудистого тонуса. Помимо этого большую роль играют фенотипические изменения сосудистых эндотелиальных клеток, а также изменения реологических параметров в сосудах микроциркуляции. При вторичном СР существенным фактором являются также структурные изменения сосудов [18]. Ключевую роль в генезе СР играет дисбаланс между вазодилататорами и вазоконстрикторами вследствие нарушений нейрогенного контроля сосудистого тонуса и продуцируемых в гемоциркуляцию медиаторов $[19,20]$. Известно, что при охлаждении повышается продукция кислородных радикалов, которые активируют Rho-киназу, вызывающую транслокацию на клеточную мембрану а2с-адренорецепторов, ответственных за вазоконстрикторные реакции $[21,22]$.

Впервые это состояние описал М. Рейно (M. Raynaud, 1862), охарактеризовав его как локальную асфиксию конечностей [23]. Позже T. Льюис (T. Lewis) ввел подразделение СР на первичный и вторичный [24]. Для верификации варианта были предложены диагностические критерии первичного (идиопатического, или болезни Рейно) [25] и вторичного (ассоциированного с другими заболеваниями) [26] СР, основанные на клинических особенностях, данных лабораторных и инструментальных исследований (табл. 3). В большинстве случаев (80-90\% от общего числа больных) СР является идиопатическим $[9,27]$.

В классических описаниях клиническая картина СР представляется как трехфазное изменение окраски кожи пальцев кистей: побледнение (побеление) - посинение (цианотичность) - покраснение [28, 29]. Первые 2 фазы изменения окраски отражают состояние вазоспазма и гипоксии, а по окончании атаки вазоспазма вследствие реактивной гиперемии кожа приобретает ярко-красную окраску. Однако трехфазность изменений окраски кожи отмечается только у 15\% больных, тогда как в 85\% случаев встречается так называемый двух- или однофазный СР [8]. Чаще всего наблюдается цианотичность пальцев кистей, обозначаемая как акроцианоз (рис. 1). Зона измененной окраски кожи резко отграничена от остальных участков. Значительная часть больных предъявляют жалобы на сенсорные нарушения (онемение, покалывание, боль) во время атаки Рейно.
Таблица 1. Заболевания и состояния, с которыми ассоциируется синдром Рейно

\begin{tabular}{|c|c|}
\hline Класс заболеваний / состояния & Нозологические формы / причинный фактор \\
\hline Аутоиммунные заболевания & $\begin{array}{l}\text { Системная склеродермия } \\
\text { Системная красная волчанка } \\
\text { Смешанное заболевание соединительной ткани } \\
\text { Дерматомиозит / полимиозит } \\
\text { Ревматоидный артрит } \\
\text { Синдром Шегрена } \\
\text { Васкулиты } \\
\text { Первичная легочная гипертензия }\end{array}$ \\
\hline Инфекционные заболевания & $\begin{array}{l}\text { Гепатиты В и C (особенно ассоциированные } \\
\text { с криоглобулинемией смешанного или 3-го типа) } \\
\text { Микоплазменная инфекция (с холодовыми } \\
\text { агглютининами) } \\
\text { Helicobacter pylori } \\
\text { Парвовирус B19 }\end{array}$ \\
\hline Неопластические синдромы & $\begin{array}{l}\text { Лимфома } \\
\text { Лейкоз } \\
\text { Миелома } \\
\text { Макроглобулинемия Вальденстрема } \\
\text { Криоглобулинемия моноклональная или 1-го типа } \\
\text { Аденокарцинома легких } \\
\text { Рак яичника } \\
\text { Ангиоцентрическая лимфома }\end{array}$ \\
\hline $\begin{array}{l}\text { Метаболические / эндокринные } \\
\text { болезни }\end{array}$ & $\begin{array}{l}\text { Атеросклероз } \\
\text { Гипергомоцистеинемия } \\
\text { Акромегалия } \\
\text { Микседема } \\
\text { Сахарный диабет } \\
\text { Феохромоцитома } \\
\text { Болезнь Фабри }\end{array}$ \\
\hline Гематологические синдромы & $\begin{array}{l}\text { Пароксизмальная ночная гемоглобинурия } \\
\text { Криофибриногенемия } \\
\text { Полицитемия }\end{array}$ \\
\hline $\begin{array}{l}\text { Индуцированные экзогенными } \\
\text { факторами }\end{array}$ & $\begin{array}{l}\text { Вибрационное повреждение } \\
\text { Воздействие винилхлорида } \\
\text { Обморожение } \\
\text { Воздействие свинца } \\
\text { Воздействие мышьяка }\end{array}$ \\
\hline $\begin{array}{l}\text { Связанные с приемом } \\
\text { лекарственных } \\
\text { препаратов, психотропных } \\
\text { и наркотических средств }\end{array}$ & $\begin{array}{l}\text { Оральные контрацептивы } \\
\text { Алкалоиды спорыньи } \\
\text { Бромокриптин } \\
\text { Бета-блокаторы } \\
\text { Противоопухолевые препараты (цисплатин, } \\
\text { блеомицин, винбластин) } \\
\text { Циклоспорин } \\
\text { Интерферон альфа } \\
\text { Метисегид } \\
\text { Кокаин }\end{array}$ \\
\hline
\end{tabular}
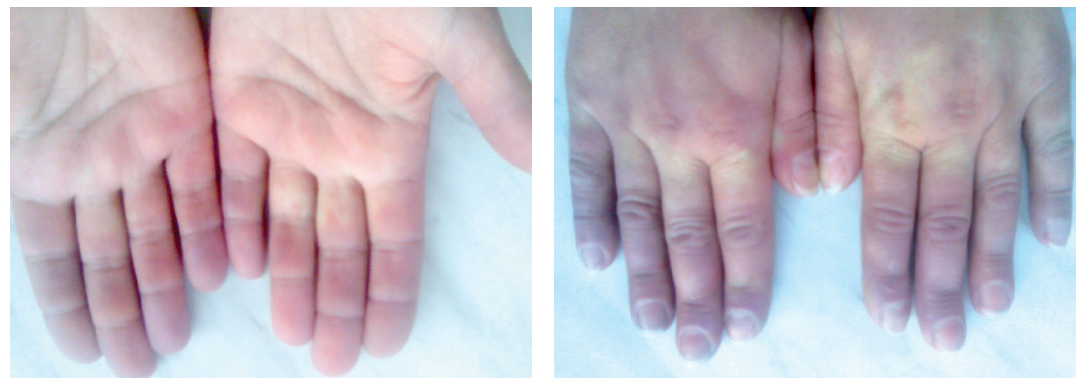

Рис. 1. Цианоз дистальных фаланг пальцев кистей во время атаки Рейно 
Таблица 2. Распространенность СР в популяции, среди женщин и мужчин, в разных странах

\begin{tabular}{lllll}
\hline \multirow{2}{*}{ Страна } & Число обследованных & Частота, \% & & \\
\cline { 3 - 5 } & & в популяции & среди женщин & среди мужчин \\
\hline Англия [1] & 12907 & 14,2 & - & - \\
Англия [2] & 413 & - & 19 & 11 \\
Голландия [3] & 508 & - & 21,2 & 10,4 \\
Швеция [4] & 2705 & - & 15,6 & - \\
Эстония [5] & 457 & - & 8,3 & 7,9 \\
Франция [6] & 2000 & 16,8 & 20,1 & 13,5 \\
Венгрия [7] & 10000 & 5,8 & - & - \\
Греция [8] & 500 & 5,2 & 6,4 & 0,9 \\
Испания [9] & 1477 & 3,7 & 4,7 & 3,2 \\
Италия [10] & 2155 & 2,1 & 3,4 & 0,5 \\
Турция [11] & 768 & 5,9 & - & - \\
США [12] & 1350 & - & 2,0 & 1,5 \\
США [13] & 1525 & - & 9,6 & 5,8 \\
\hline
\end{tabular}

СР присущи следующие клинические особенности:

- наиболее часто изменения окраски наблюдаются на пальцах кистей;

- изменения начинаются на одном пальце, в дальнейшем распространяются на другие пальцы и становятся симметричными на обеих кистях;

- наиболее часто вовлекаются II-IV пальцы кистей, большой палец обычно остается неизмененным;

- изменение окраски кожи может отмечаться и на других участках - ушные раковины, кончик носа, лицо, над коленями;

- во время атак Рейно возможно появление сетчатого ливедо на конечностях, которое проходит после завершения вазоспазма;

- в редких случаях наблюдается поражение языка, что проявляется его онемением и преходящими нарушениями речи (речь становится невнятной, смазанной).

Вазоспазм обычно длится 15-20 минут и завершается быстрым восстановлением кровотока, о чем свидетельствует интенсивно розовая окраска кожи (реактивная гиперемия). В то же время частота и продолжительность эпизодов вазоспазма могут варьировать как у разных больных, так и у одних и тех же пациентов в разное время года (зимой более интенсивные проявления, чем летом).

Диагноз СР устанавливается в первую очередь на основании жалоб и клинических симптомов и считается достоверным при положительном ответе на 3 следующих вопроса:
1. Отмечается ли необычная чувствительность пальцев к холоду?

2. Изменяется ли цвет пальцев под воздействием холода?

3. Становятся ли они белыми и/или синеватыми?

При этом надо учитывать, что чувствительность пальцев кистей к холоду встречается и у абсолютно здоровых людей. Так, почти $12 \%$ из 7000 человек ответили утвердительно на вопрос о повышенной чувствительности пальцев или конечностей в целом к холодной температуре [30]. Более того, холодная кожа или неочерченная крапчатая окраска кожи пальцев, кистей и конечностей считается нормальным ответом на воздействие холода. В этой связи отметим, что для СР высоко чувствительным (94-100\%) и высоко специфичным (75-78\%) признаком служит побеление пальцев [1].

Всем больным с впервые выявленным СР необходимо проводить дополнительные исследования для определения его клинической формы. В первую очередь следует уточнить:

- имеются ли у пациента симптомы заболеваний соединительной ткани, с которыми наиболее часто ассоциируется СР (артриты, миалгии, лихорадка, «сухой» синдром, кожная сыпь, кардиопульмональные нарушения);

- принимает ли больной на момент исследования какие-либо препараты, особенно химиотерапевтические средства;

- подвергается ли больной вибрации или другим механическим воздействиям, травмирующим кисти; 
- связаны ли эпизоды СР с определенными позиционными изменениями.

При дифференциации первичного и вторичного СР следует также учитывать: чем раньше происходит дебют СР, тем больше вероятность, что в данном случае представлен его первичный вариант. Средний возраст начала первичного $\mathrm{CP}$ - 14 лет, и только в $27 \%$ случаев он развивается в возрасте 40 лет и старше [31]. В 1/4 случаев первичного СР признаки этого состояния имеются У родственников первой линии [32].

На вторичный характер СР, как правило, указывают следующие признаки:

- поздний возраст начала;

- мужской пол;

- болезненные эпизоды вазоспазма с признаками тканевой ишемии (изъязвления);

- асимметричный характер атак.

Важно помнить о том, что клинические признаки заболевания, с которым ассоциируется СР, могут развиться по истечении нескольких месяцев или лет после появления первых эпизодов вазоспазма.

Инструментальные и лабораторные методы исследования направлены прежде всего на уточнение клинического варианта СР - первичный или вторичный, а также на выявление заболевания, с которым этот синдром может быть ассоциирован. Наиболее информативным среди инструментальных методов является капилляроскопия ногтевого ложа. Метод позволяет визуально оценить локальную капиллярную сеть ногтевого ложа и обнаружить структурные изменения капилляров и нарушения капиллярного кровотока. При первичном СР структурные изменения капилляров отсутствуют, но выявляются функциональные нарушения в виде выраженного снижения скорости кровотока в капиллярах или внутрикапиллярного стаза. Для вторичного СР характерны изменения числа, размеров и формы капиллярных петель, признаки деструкции капилляров, редукция капиллярной сети (рис. 2).

Для дифференциации первичного и вторичного СР используют и другие инструментальные исследования:

- лазерную допплеровскую флоуметрию - метод количественной оценки кожного кровотока; с помощью провокационных тестов выявляют повышенный вазоспазм и снижение вазодилатационного потенциала;

- термографию - метод косвенной оценки кожного кровотока по уровню температуры кожи; время восстановления исходной температуры кожи после охлаждения и градиент
Таблица 3. Диагностические критерии первичного и вторичного СР

\begin{tabular}{ll}
\hline Первичный СР & Вторичный СР \\
\hline $\begin{array}{l}\text { Эпизоды вазоспазма под влиянием холода } \\
\text { или эмоционального стресса }\end{array}$ & Возраст развития болезни более 30 лет \\
Симметричность атак & Эпизоды вазоспазма сопровождаются \\
Отсутствие некроза, изъязвений или & болью, асимметричные или \\
гангрены & ассоциируются с ишемическими \\
Отсутствие анамнестических данных & повреждениями кожи \\
и объективных признаков вторичного СР & Клинические признаки, характерные для \\
Нормальные капилляры ногтевого ложа & заболеваний соединительной ткани \\
Нормальные значения скорости оседания & Признаки поражения микроциркуляторных \\
эритроцитов & сосудов при капилляроскопии ногтевого \\
Отрицательные результаты исследования & ложа \\
антинуклеарных антител & \\
\hline СР - синдром Рейно &
\end{tabular}

Таблица 4. Причины акроцианоза

\begin{tabular}{ll}
\hline Тип акроцианоза & Причина \\
\hline Односторонний & Локальная травма \\
& Локальная инфекция \\
& Опухоль шеи, сдавливающая нервно-сосудистый \\
пучок (нейробластома, опухоль ганглия) & Тромбоэмболия артерий ладонной дуги \\
& Рефлекторная симпатическая дистрофия \\
& Обморожение \\
Двухсторонний акроцианоз & Юношеский акроцианоз \\
& Обморожение \\
& Ознобление \\
Рефлекторная симпатическая дистрофия \\
Гипоксемия \\
Метгемоглобинемия \\
Врожденные пороки сердца \\
Феохромоцитома \\
Фульминантная пурпура
\end{tabular}
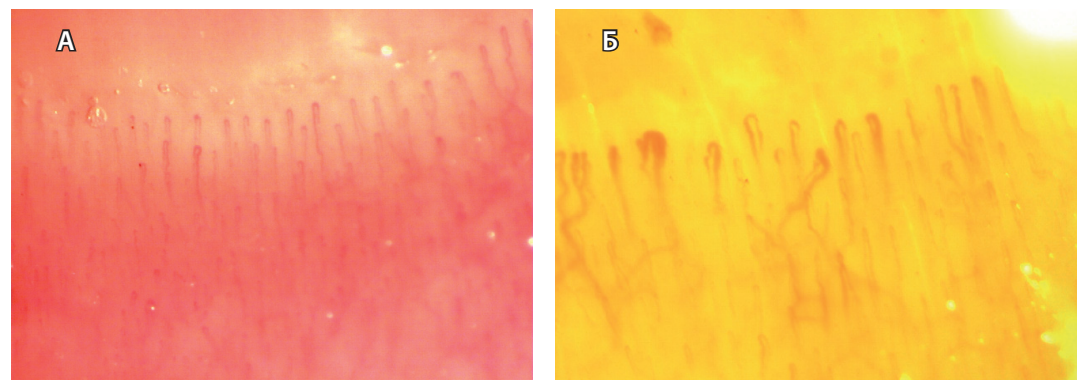

Рис. 2. Капилляроскопия ногтевого ложа при СР: A - первичный СР, нормальная капилляроскопическая картина; Б - расширенные капилляры и микрогеморрагии указывают на вторичный характер СР

температуры вдоль пальца отражают выраженность поражения сосудов [33];

- плетизмографию - метод, позволяющий измерить давление крови в пальцевой артерии; снижение давления на 70\% и больше после локального охлаждения указывает на вторичный характер СР (чувствительность - 97\%); 


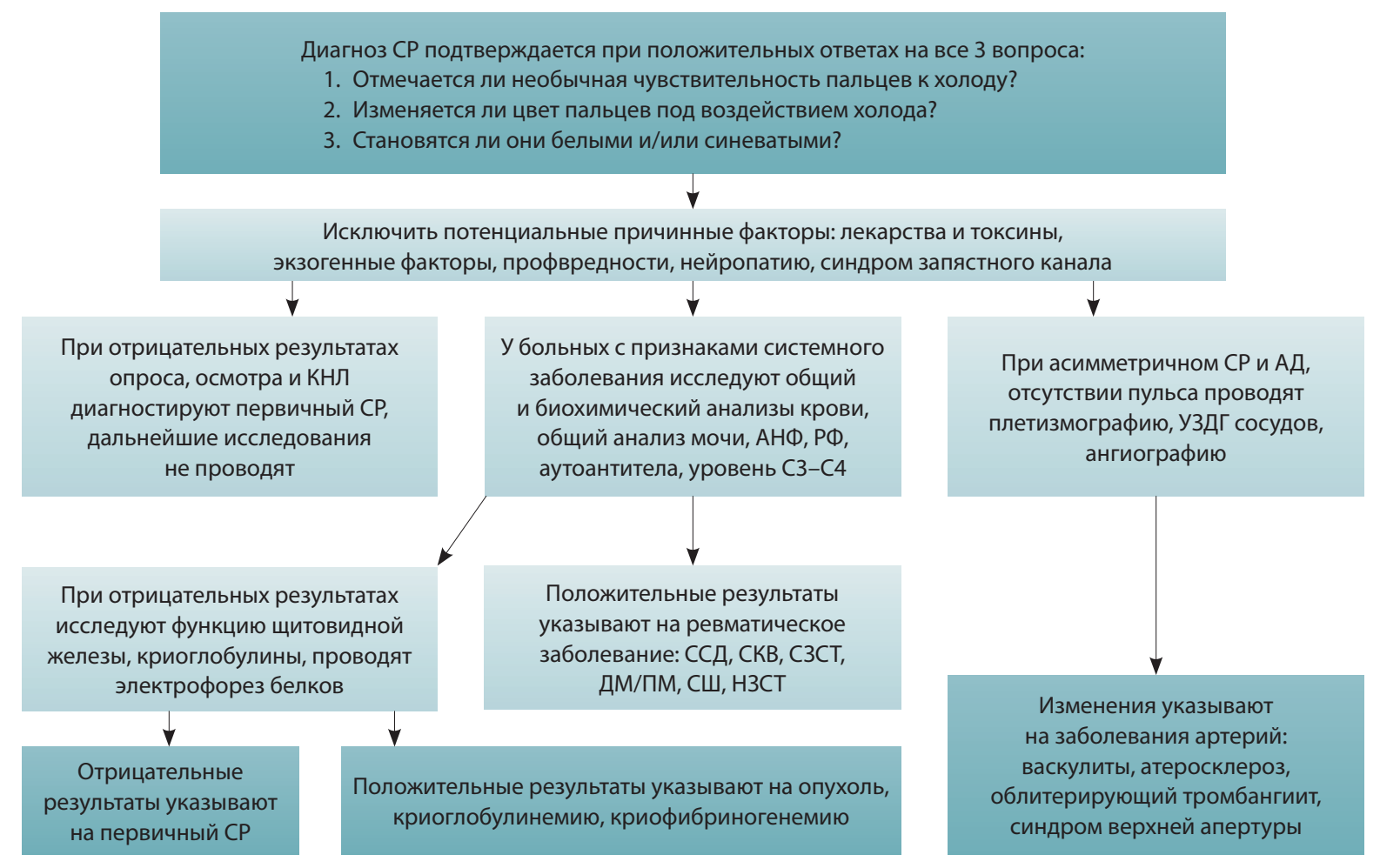

Рис. 3. Диагностический алгоритм синдрома Рейно; СР - синдром Рейно, КНЛ - капилляроскопия ногтевого ложа,

АНФ - антинуклеарный фактор, РФ - ревматоидный фактор, АД - артериальное давление, УзДГ - ультразвуковая допплерография, ССД - системная склеродермия, СКВ - системная красная волчанка, СЗСТ - смешанное заболевание соединительной ткани,

ДМ - дерматомиозит, ПМ - полимиозит, СШ - синдром Шегрена, НЗСТ - недифференцированное заболевание соединительной ткани

для системной склеродермии характерно снижение давления до 0 при $30^{\circ} \mathrm{C}$ (специфичность - 100\%);

- цветное допплеровское ультразвуковое сканирование - метод, дающий возможность визуализировать и измерить диаметр дигитальной артерии, оценить скорость кровотока, дифференцировать первичный и вторичный CP [34].

Для ранней и дифференциальной диагностики первичного и вторичного СР рекомендуется придерживаться алгоритма, представленного на рис. 3. В первую очередь следует проводить дифференциальную диагностику СР с акроцианозом, который характеризуется стойким изменением окраски (цианозом) дистальных отделов конечностей, усиливающимся под влиянием холода [35, 36] (табл. 4, [37]). Юношеский акроцианоз может быть вызван СР, в этих случаях необходима лекарственная профилактика его осложнений [38, 39]. Некоторые состояния могут быть ошибочно расценены как СР. К ним относятся карпальный туннельный синдром, рефлекторная симпатическая дистрофия, синдром верхней апертуры. Все эти синдромы связаны с механическим повреждением нервно-сосудистого пучка верхних конечностей. У пациентов с первичным СР во время атаки Рейно может появляться сетчатое ливедо, которое исчезает по завершении вазоспазма. Однако если сетчатое ливедо имеет устойчивый характер, следует исключить ассоциацию СР с такими заболеваниями, как васкулиты, антифосфолипидный синдром и окклюзивные поражения периферических сосудов. Пациенты с заболеваниями периферических сосудов, сопровождающимися снижением кровотока и ишемией, часто жалуются на замерзание конечностей, их онемение и покалывание. При СР в отличие от заболеваний периферических сосудов указанные симптомы наблюдаются только во время вазоспазма и полностью проходят после завершения атаки Рейно и восстановления кровотока. Особое внимание следует обратить на прием ряда препаратов, в том числе широко применяемых в клинической практике (см. табл. 1).

Следует отметить, что антинуклеарный фактор имеет относительно низкую прогностическую ценность для заболеваний соединительной ткани (30\%), тогда как обнаружение болезнь-специфических аутоантител значительно 
повышает вероятность вторичного характера СР. Приблизительно у 15-20\% больных СР, у которых выявляются специфические аутоантитела и/или капилляроскопические изменения, но отсутствуют симптомы заболеваний соединительной ткани, в дальнейшем (обычно в течение 2 лет) развивается то или иное заболевание соединительной ткани. Наиболее часто вторичный СР ассоциируется с системной склеродермией, системной красной волчанкой, другими заболеваниями соединительной ткани, гематологическими нарушениями и приемом некоторых лекарств.

Первичный СР имеет благоприятные течение и прогноз. Тем не менее течение СР может существенно варьировать у разных больных: при длительном наблюдении (в среднем 12 лет) 307 женщин с СР у $38 \%$ из них изменений не было, у $36 \%$ отмечалось уменьшение частоты и выраженности атак Рейно, у 16\%, наоборот, - нарастание выраженности клинических симптомов, а еще у $10 \%$ проявления СР исчезли [40]. Метаанализ большого числа наблюдений показал, что у $13 \%$ больных с СР в среднем через 10 лет (0,6-27,9 года) развивались признаки другого заболевания, при этом отмечалось существенное преобладание склеродермической группы болезней [41]. При вторичной форме прогноз определяется в первую очередь заболеванием, с которым СР ассоциируется.

Лечение больных с СР комплексное, включающее как медикаментозную терапию, так и физические методы. Целесообразность хирургического лечения (шейная симпатэктомия) считается спорной, так как оно дает только временное улучшение. При выраженных ишемических нарушениях у больных с вторичным СР более эффективна дигитальная симпатэктомия.

При лечении СР следует придерживаться следующих принципов:

- характер и объем терапии зависят от интенсивности атак Рейно и осложнений;

- лечение считается успешным при уменьшении выраженности атак и отсутствии новых ишемических повреждений;

- при первичном СР лекарственная терапия показана преимущественно в зимнее время;

- при вторичном СР всем больным следует проводить длительную лекарственную терапию;

- при неэффективности монотерапии возможно сочетание препаратов синергичного действия из разных групп.

Для лечения СР применяют широкий спектр лекарственных средств разных классов, отличающихся механизмом действия (подробно см. [42]).

В заключение отметим: поскольку СР широко распространен среди населения и у части больных может быть ассоциирован с различными заболеваниями, он является предметом интереса врачей разных специальностей: терапевтов, ревматологов, невропатологов, педиатров, ангиохирургов, гинекологов и др. Стандартизированный подход к диагностике и дифференциальной диагностике данного состояния позволит обеспечить его раннее выявление, своевременное лечение и профилактику осложнений. (е)

\section{Литература (References)}

1.Palmer KT, Griffin MJ, Syddall H, Pannett B, Cooper C, Coggon D. Prevalence of Raynaud's phenomenon in Great Britain and its relation to hand transmitted vibration: a national postal survey. Occup Environ Med. 2000;57(7):448-52.

2. Silman A. Raynaud's phenomenon in general practice. Nurs times. 1990;86(46):52-3.

3. Bartelink ML, Wollersheim $H$, van de Lisdonk $E$, Spruijt R, van Weel C. Prevalence of Raynaud's phenomenon. Neth J Med. 1992;41(3-4):149-52.

4. Leppert J, Aberg H, Ringqvist I, Sörensson S. Raynaud's phenomenon in a female population: prevalence and association with other conditions. Angiology. 1987;38(12):871-7.

5. Valter I, Maricq HR. Prevalence of Raynaud phenomenon in Tartu and Tartumaa, southern Estonia. Scand J Rheumatol. 1997;26(2):117-24.

6. Maricq HR, Carpentier PH, Weinrich MC, Keil JE, Franco A, Drouet P, Ponçot OC, Maines MV. Geographic variation in the prevalence of Raynaud's phenomenon: Charleston, SC, USA, vs Tarentaise, Savoie, France. J Rheumatol. 1993;20(1):70-6.

7. Czirják L, Kiss CG, Lövei C, Süto G, Varjú C, Füzesi Z, Illés T, Nagy Z. Survey of Raynaud's phenomenon and systemic sclerosis based on a representative study of 10,000 south-Transdanubian Hungarian inhabitants. Clin Exp Rheumatol. 2005;23(6):801-8.

8. Voulgari PV, Alamanos Y, Papazisi D, Christou K, Papanikolaou C, Drosos AA. Prevalence of Raynaud's phenomenon in a healthy Greek population. Ann Rheum Dis. 2000;59(3):206-10.

9. Riera G, Vilardell M, Vaqué J, Fonollosa V, Bermejo B. Prevalence of Raynaud's phenomenon in a healthy Spanish population. J Rheumatol. 1993;20(1):66-9.

10. De Angelis R, Salaffi F, Grassi W. Raynaud's phenomenon: prevalence in an Italian population sample. Clin Rheumatol. 2006;25(4):506-10.

11. Onbaşi K, Sahin I, Onbaşi O, Ustün Y, Koca D. Raynaud's phenomenon in a healthy Turkish population. Clin Rheumatol. 2005;24(4): 365-9.

12. Suter LG, Murabito JM, Felson DT, Fraenkel L. The incidence and natural history of Raynaud's phenomenon in the community. Arthritis Rheum. 2005;52(4):1259-63.

13. Fraenkel L, Zhang $Y$, Chaisson CE, Maricq HR, Evans SR, Brand F, Wilson PW, Felson DT. Different factors influencing the expression of Raynaud's phenomenon in men and women. Arthritis Rheum. 1999;42(2):306-10.

14. Maricq HR, Carpentier PH, Weinrich MC, Keil JE, Palesch Y, Biro C, Vionnet-Fuasset M, Jiguet $M$, Valter I. Geographic variation in the prevalence of Raynaud's phenomenon: a 5 region comparison. J Rheumatol. 1997;24(5): 879-89.

15. Jones GT, Herrick AL, Woodham SE, Baildam EM, Macfarlane GJ, Silman AJ. Occurrence of Raynaud's phenomenon in children ages 12-15 years: prevalence and association with 
other common symptoms. Arthritis Rheum. 2003:48(12):3518-21.

16. Harada N, Ueda A, Takegata S. Prevalence of Raynaud's phenomenon in Japanese males and females. J Clin Epidemiol. 1991;44(7):649-55.

17. Ling SM, Wigley FM. Raynaud's phenomenon in older adults: diagnostic considerations and management. Drugs Aging. 1999;15(3):183-95.

18. Bakst R, Merola JF, Franks AG Jr, Sanchez M. Raynaud's phenomenon: pathogenesis and management. J Am Acad Dermatol. 2008;59(4): 633-53.

19. Kahaleh B, Matucci-Cerinic M. Raynaud's phenomenon and scleroderma. Dysregulated neuroendothelial control of vascular tone. Arthritis Rheum. 1995;38(1):1-4.

20. Herrick AL. Pathogenesis of Raynaud's phenomenon. Rheumatology (Oxford). 2005;44(5): 587-96.

21. Bailey SR, Eid AH, Mitra S, Flavahan S, Flavahan NA. Rho kinase mediates cold-induced constriction of cutaneous arteries: role of alpha2C-adrenoceptor translocation. Circ Res. 2004;94(10):1367-74.

22. Bailey SR, Mitra S, Flavahan S, Flavahan NA. Reactive oxygen species from smooth muscle mitochondria initiate cold-induced constriction of cutaneous arteries. Am J Physiol Heart Circ Physiol. 2005;289(1):H243-50.

23. Raynaud M. Local asphyxia and symmetrical gangrene of the extremities. Paris: MD Thesis; 1862. In: English translation: selected monographs. London: New Sydenham Society; 1888.

24. Lewis T. Experiments relating to the peripheral mechanisms involved in spasmodic arrest of the circulation in the fingers, a variety of Raynaud's disease. Heart. 1929;15:7-101.
25. LeRoy EC, Medsger TA Jr. Raynaud's phenomenon: a proposal for classification. Clin Exp Rheumatol. 1992;10(5):485-8.

26. Kallenberg CG. Early detection of connective tissue disease in patients with Raynaud's phenomenon. Rheum Dis Clin North Am. 1990;16(1):11-30.

27. De Angelis R, Del Medico P, Blasetti P, Cervini C. Raynaud's phenomenon: clinical spectrum of 118 patients. Clin Rheumatol. 2003;22(45):279-84.

28. Allen EV, Brown GE. Raynaud's disease: a critical review of minimal requisites for diagnosis. Am J Med Sci. 1932;183:187-200.

29. Summers A. From white to blue to red: Raynaud's phenomenon. Emerg Nurse. 2005;13(7):18-20.

30. Maricq $H R$, Weinrich MC, Keil JE, Smith EA Harper FE, Nussbaum Al, LeRoy EC, McGregor AR, Diat F, Rosal EJ. Prevalence of scleroderma spectrum disorders in the general population of South Carolina. Arthritis Rheum. 1989;32(8):998-1006.

31. Planchon B, Pistorius MA, Beurrier P, De Faucal P. Primary Raynaud's phenomenon. Age of onset and pathogenesis in a prospective study of 424 patients. Angiology. 1994;45(8): 677-86.

32. Freedman RR, Mayes MD. Familial aggregation of primary Raynaud's disease. Arthritis Rheum. 1996;39(7):1189-91.

33. Herrick AL, Clark S. Quantifying digital vascular disease in patients with primary Raynaud's phenomenon and systemic sclerosis. Ann Rheum Dis. 1998;57(2):70-8.

34. Keberle M, Tony HP, Jahns R, Hau M, Haerten R, Jenett $M$. Assessment of microvascular chan- ges in Raynaud's phenomenon and connective tissue disease using colour doppler ultrasound. Rheumatology (Oxford). 2000;39(11): 1206-13.

35. Wigley FM. Clinical practice. Raynaud's phenomenon. N Engl J Med. 2002;347(13):1001-8.

36. DiMaio AM, Singh J. The infant with cyanosis in the emergency room. Pediatr Clin North Am. 1992;39(5):987-1006.

37. Sharathkumar AA, Castillo-Caro P. Primary Raynaud's phenomenon in an infant: a case report and review of literature. Pediatr Rheumatol Online J. 2011;9:16.

38. Krieger I, Brough AJ. Raynaud's phenomenon in an infant. J Pediatr. 1972;80(1):145-51.

39. Nigrovic PA, Fuhlbrigge RC, Sundel RP. Raynaud's phenomenon in children: a retrospective review of 123 patients. Pediatrics. 2003;111(4 Pt 1):715-21.

40. García de la Peña-Lefebvre $P$, Rodríguez Rubio $S$, Valero Expósito M, Carmona L, Gámir Gámir ML, Beltrán Gutiérrez J, Díaz-Miguel C, Orte Martínez J, Zea Mendoza AC. Long-term experience of bosentan for treating ulcers and healed ulcers in systemic sclerosis patients. Rheumatology (Oxford). 2008;47(4):464-6.

41. Spencer-Green G. Outcomes in primary Raynaud phenomenon: a meta-analysis of the frequency, rates, and predictors of transition to secondary diseases. Arch Intern Med. 1998;158(6):595-600.

42. Алекперов РТ. Синдром Рейно в практике ревматолога. Современная ревматология. 2014;(2):48-57.

(Alekperov RT. [Raynaud's phenomenon in the rheumatologist's practice]. Sovremennaya revmatologiya. 2014;(2):48-57. Russian).

\title{
Raynaud's phenomenon: a multidisciplinary problem
}

\author{
Alekperov R.T.
}

Raynaud's phenomenon (RP) is a common medical condition with prevalence in the population about $3-5 \%$. RP is subdivided into primary form manifesting mainly in children and adolescents, and secondary RP affecting elder patients. Secondary RP is frequently associated with systemic rheumatic disorders, endocrine and hematological diseases and certain infections. It also may be due to exogenous factors. Thus, RP is an actual problem in the practice of rheumatologists, pediatric physicians, infectious diseases specialists, hematologists and other medical practitioners. This clinical lecture discusses in detail current approaches to diagnosis and differential diagnosis of RP.

Key words: Raynaud's phenomenon, diagnosis, differential diagnosis.

'Moscow Regional Research and Clinical Institute (MONIKI); 61/2 Shchepkina ul., Moscow, 129110, Russian Federation ${ }^{2}$ V.A. Nasonova Research Institute of Rheumatology, Russian Academy of Medical Sciences; 34A Kashirskoe shosse, Moscow, 115522, Russian Federation

Alekperov Rizvan Tair ogly - MD, PhD, Professor, Internal Diseases Department, Postgraduate Medical School', Senior Research Associate ${ }^{2}$

$\square$ 61/2 Shchepkina ul., Moscow, 129110, Russian Federation. Tel.: +7 (495) 6816840 E-mail: ralekperov@list.ru 